\title{
PEMODELAN APLIKASI BOOKING TIKET MENGGUNAKAN UNIFIED MODELING LANGUAGE
}

\author{
Hutrianto ${ }^{1}$, Baibul Tujni ${ }^{2}$ \\ ${ }^{1}$ Program Studi Teknik Informatika, Universitas Bina Darma, Palembang \\ ${ }^{1}$ Program Studi Komputerisasi Akuntansi, Universitas Bina Darma, Palembang \\ e-mail:*1'hutrianto@binadarma.ac.id, ${ }^{2}$ baibul.tujni@binadarma.ac.id
}

\begin{abstract}
Abstrak
Pengembangan sebuah aplikasi merupakan inovasi untuk menyelesaikan masalah. Untuk melakukan pengembangan aplikasi terdapat berbagai teknik pengembangan. pengembangan aplikasi berbasis web dan pengembangan aplikasi berbasis mobile memiliki perlakuan yang berbeda. Namun yang paling penting dari proses pengembangan aplikasi adalah pemodelan informasi aplikasi itu sendiri. karena dengan adanya pemodelan proses pengembangan akan lebih terarah dan sistematis. Pemodelan memiliki kemapuan menggambarkan cetak biru dari aplikasi yang akan dikembangkan. Untuk itu pada penelitian ini akan dilakukan pemodelan aplikasi menggunakan unified modeling language dengan tiga tahapan yaitu kebutuhan informasi, pemodelan dan pembuatan prototype. Pemodelan dilakukan guna mempermudah proses pengembangan dengan kasus aplikasi booking tiket. Penggunaan unified modeling language dalam melakukan pemodelan juga disebabkan notasi unified modeling language memiliki kemampuan dalam menggambarkan berbagai proses dalam sebuah aplikasi yang dikembangkan. Hasil dari penelitian ini berupa pemodelan aplikasi dengan unified modeling language yang digambarkan dalam tiga bentuk notasi yaitu structure diagram yang digambarkan dalam bentuk class diagram, communication diagram yang digambarkan dalam bentuk activity diagram dan behavior diagram yang digambarkan dalam bentuk use case diagram. Pemodelan aplikasi juga diimplementasikan dalam bentuk prototype aplikasi dengan fitur pemesanan tiket, proses konfirmasi, jadwal keberangkatan serta pengelolaan data terkait dengan proses pemesanan tiket.
\end{abstract}

Kata kunci : Pemodelan; Aplikasi; Booking; UML

\begin{abstract}
The development of an application is an innovation to solve problems. To develop applications, there are various development techniques. Web-based application development and mobile-based application development have different treatments. However, the most important part of the application development process is modeling the application information itself. because with the modeling the development process will be more directed and systematic. Modeling could describe the blueprint of the application to be developed. For this reason, this research will conduct application modeling using a unified modeling language with three stages, namely information needs, modeling and prototyping. Modeling is done in order to simplify the development process with the ticket booking application case. The use of unified modeling language in modeling is also due to the notation that unified modeling language could describe various processes in a developed application. The results of this study are in the form of application modeling with a unified modeling language which is depicted in three notation forms, namely a structure diagram depicted in the form of a class diagram, a communication diagram depicted in the form of an activity diagram and a behavior diagram depicted in the form of a use case diagram. Application modeling is also implemented in the form of application prototypes with ticket booking features, confirmation processes, departure schedules and data management related to the ticket booking process.
\end{abstract}

Keywords : Modeling; Application; Booking; UML 


\section{PENDAHULUAN}

Teknologi informasi dan komunikasi atau sering dikenal dengan TIK saat ini telah digunakan diberbagai level kehidupan dan kegiatan kehidupan. Tidak terkecuali dalam mendukung proses bisnis dari kegiatan usaha yang dilakukan oleh seseorang ataupun badan usaha. Penggunaan TIK itu sendiri tentunya selain dari untuk membantu proses bisnis juga digunakan untuk menjawab tantangan zaman dan persaingan usaha itu sendiri [1]. Sehingga penggina TIK menjadi keharusan agar badan usaha memiliki nilai ketahanan dalam persaingan.

Salah satu jenis usaha yang saat ini dituntut untuk melakukan perbaikan terutama dalam bidang TIK itu sendiri yaitu perusahaan transportasi darat jenis angkutan kota atau antar provinsi. Salah satu badan usaha tersebut yaitu Yonda Prima. Yoanda Prima sendiri salah satu badan usaha yang bergerak dalam bindang transportasi darat atau sering dikenal dengan agen pariwisata yang ada di Kota Palembang. Kegiatan usaha Yonda Prima itu sendiri tentunya berkaitan langsung dengan dunia pariwisata terutama transportasi perjalanan wisata. Kegiatan usaha tersebut biasanya dilakukan dengan bekerjasama dengan berbagai instasi ataupun individu.

Sesuai dengan proses bisinis yang ada tentunya terdapat beberapa kendala atau permasalahan yang sering muncul terutama terkait dengan proses pemesanan tiket. Dimana permasalahan tersebut yaitu pemilihan jenis bus dan tentunya tempat pada bus tersebut. Kondisi tersebut tentunya berkaitan erat dengan kepuasan pelanggan terkait dengan layanan bus. Konidisi yang biasanya terjadi adalah calon pelanggan menelpon atau datang langsung ke tempat berada, namun saat ini tentunya banyak calon pelanggan yang bertanya atau memesan melalui telepon sehingga petugas harus menjelaskan secara detail tentang ketersediaan kursi bus. Dengan demikian tentunya akan membutuhkan waktu untuk menejelaskan kepada calon pelanggan tersebut.

Permasalahan yang terjadi tersebut tentunya dapat diatas dengan memanfaatkan TIK, pemanfaatan tersebut dapat dilakukan dengan cara menyediakan aplikasi khusus untuk melakukan pemesanan tiket dan pengelolaan tiket agar efisiensi dalam proses pemesanan dapat terjadi. Aplikasi yang disediakan tentunya dapat mendukung operasional dengan mudah, baik dasisi calon pelanggan maupun dari sisi pengelola bus itu sendiri [2]. Untuk itu penggunaan media yang tepat juga menjadi keharusan, seperti aplikasi berbasis mobile yang diperuntukkan bagi calon pelanggan dan berbasis web bagi pengelola bus. "

Untuk mendapatkan aplikasi tersebut sesuai dengan kebutuhan maka dibutuhkan pemodelan aplikasi. maka dalam penelitian ini akan dilakukan pemodelan aplikasi booking tiket agar dapat diimplementasikan sebagai upaya pemenuhan kebutuhan dalam mengatsi permasalahan yang ada. Pemodelan adalah proses pengembangan blueprint dari aplikasi booking tiket yang akan dikembangkan [3]. Pemodelan juga digunakan untuk menyederhanakan permsasalah dalam pengembangan aplikasi [4]. Untuk menggambarkan atau membuat pemodelan aplikasi salah satu alat bantu yang dapat digunakan yaitu unified modeling language (UML). UML sendiri memiliki kemampuan untuk menggambarkan atau memetakan kebutuhan aplikasi dan UML juga bukanlah sebuah bahasa pemrograman [5]. Diagram yang terdapat pada UML sendiri terdapat berbagai jenis diagram yang dibagi menjadi tiga jenis yaitu structure diagram, behavior diagram dan interaction diagram [6]."

Berdasarkan uraian yang telah dikemukakan sebelumnya maka penelitian ini akan dilakukan pemodelan aplikasi booking tiket menggunakan pendekatan 
unified modeling language (UML). Hasil dari pemodelan ini tentunya dapat dijadikan rujukan dalam pengembangan aplikasi booking tiket agar dapat mengatasi permaslaahan yang dihadapi oleh berbagai pihak baik itu calon pelanggan, pelanggan maupun pihak pengelola bus itu sendiri.

\section{TINJAUAN PUSTAKA}

Tinjauan pustaka atau teori berkaitan dengan topik penelitian yang dilakukan dapat dijelaskan sebagai berikut:

\subsection{Pemodelan}

Pemodelan merupakan alat bantu dalam proses pengembangan sebuah perangkat lunak atau aplikasi [7]. Selain itu juga dengan adanya sebuah pemodelan akan terlihat bagaimana blueprint sebuah aplikasi dan mempermudah memahami sebuah aplikasi yang akan dibuatm [8]. Pemodelan dapat dilakukan dengan cara pemodelan visual yang menekankan pada blueprint dari sebuah aplikasi dan menggambarkan bagaimana komponen saling terkoneksi dan berinteraksi sehingga informasi detail dari aplikasi dapat terlihat dengan jelas [9].

Pemodelan visual dapat dilakukan menggunakan unified modeling language $(U M L)$, karena UML merupakan salah satu pemodelan yang mengedepankan objek dan dapat digunakan sebagai penyederhanaan permasalahan dan mudah dipahami [10]. UML memiliki konsep abstraksi yaitu structure classification, dynamic behavior, dan model management [11]. Dari tiga konsep abstraksi yang dimiliki UML maka pendefenisian dapat dilakukan dalam berbagai diagram yaitu use case diagram untuk menggambarkan kelakukan sistem yang dibuat, activity diagram unuk menggambarkan alur kerja sistem, sequence diagram untuk menggambarkan kerja objek, class diagram untuk menggambarkan bagaimana operasi dilakukan, dan deployment diagram untuk menggambarkan komponen sistem disatukan. UML bukan dalam bentuk bahasa pemrograman namun bentuk dari model yang dibuat dengan kemapuan berhubungan dengan bahasa pemrogrman dan dimungkinkan membuat pemetaan [12].

\subsection{Aplikasi}

Aplikasi merupakan salah satu jenis program komputer yang dapat digunakan dan dibentuk menggunakan perintah program komputer dengan tujuan tertentu [13]. Namun secara istilah aplikasi juga dapat dikatakan program yang siap untuk digunakan untuk melaksanakan fungsi tertentu yang dapat digunakan oleh pengguna. Selain itu juga aplikasi berfungsi untuk memecahkan masalah baik untuk melakukan pemrosesan data ataupun pengolahan data menjadi informasi [14]. Selanjutnya pengertian aplikasi menurut Kamus Besar Bahasa Indonesia (KBBI), "Aplikasi adalah penerapan dari rancang sistem untuk mengolah data yang menggunakan aturan atau ketentuan bahasa pemrograman tertentu".

\subsection{Penelitian Terdahulu}

Kajian pemodelan UML sendiri banyak dilakukan diantaranya pemodelan aplikasi penanganan pelanggaran lalu lintas, dalam kajian ini dilakukan perancangan aplikasi untuk memberikan layanan operasional penanganan pelanggaran lalu lintas. Proses perancangan digunakan pemodelan UML sebagai proses penggambaran bagaimana aplikasi akan dikembangkan dan dapat dijadikan acuan dalam proses pengembangan [15]. Kajian yang lain yaitu pemodelan UML digunakan untuk melakukan perancangan sistem informasi manajemen zakat, infaq, shadaqoh, waqaf dan hibah (ZISWAH), diagram yang digunakan yaitu use case diagram dan activity diagram. Hasil perancangan dalam bentuk pemodelan UML 
digunakan sebagai acuan dalam pengembangan sistem informasi majamen ZISWAH [16]. Selain dua kajian tersebut kajian lain berkaitan dengan pemodelan UML adalah penggunaan UML dalam tranformasi bahasa XLM ke dalam Field Programmable Gate Arrays (FPGAs) agar dapat terbaca oleh mesin, dalam kajian ini juga dibahas bagaimana spesifikasi sistem dalam bidang kontroler yang digambarkan dalam notasi UML menggunakan hierarchical concurrent finite state machines (HCFSMs) [17].

\section{METODOLOGI PENELITIAN}

\subsection{Prosedur Penelitian}

\section{Penelitian pemodelan aplikasi} booking tiket menggunakan unified modeling language menggunakan metode penelitian deskriptif. Metode ini merupakan metode penelitian yang menjelasakan fakta sesuai fenomena yang dilihat dari sudut pandang peneliti. Metode ini juga dapat memberikan dan menjabarkan fakta secara procedural sehingga mudah untuk dipahami dan tentunya dari sudut pandang peneliti.

Sedangkan untuk melakukan penelitian maka proses pengerjaan penelitian sendiri seperti yang diperlihatkan pada Gambar 1 berikut ini.

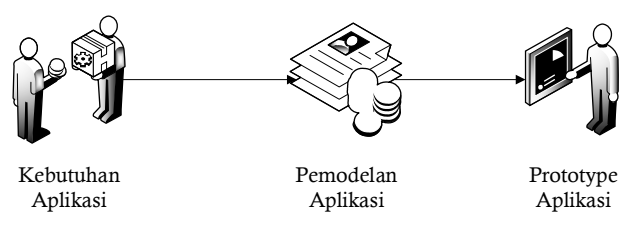

Gambar 1. Proses Penelitian

Dari Gambar 1 dapat ketahui bahwa proses penelitian pemodelan aplikasi booking tiket menggunakan unified modeling language memiliki tiga tahapan proses penelitian yaitu “(1) Penentuan kebutuhan aplikasi, (2) Melakukan pemodelan aplikasi dan (3) Pembuatan prototype aplikasi. Pada proses penentuan kebutuhan aplikasi dilakukan identifikasi kebutuhan yaitu berupa proses pemesanan dan pengaturan pembelian tiket dan juga jenis tiket yang ditawarkan sesuai dengan kondisi pada objek. Proses selanjutnya yaitu pemodelan aplikasi, pada proses ini dilakukan pemodelan menggunakan unified modeling language (UML). Jenis pemodelan yang digunakan yaitu "behavior diagram, interaction diagram dan communication diagram". Terakhir adalah pembuatan prototype aplikasi, dimana pada tahapan ini dibangun aplikasi booking tiket sesuai dengan kebutuhan aplikasi sesuai dengan hasil pemodelan.

\subsection{Pemodelan Aplikasi}

Pemodelan aplikasi merupakan proses pembentukkan struktur aplikasi dari kebutuhan pengguna atau pihak terkait. Proses pertama yaitu melakukan pembentukkan behavior diagram atau diagram tingkah lagu pengguna. Diagram ini digunakan untuk menggambarkan bagaimana tingkah laku dari aplikasi yang dibuat terhadap pengguna [18]. Behavior diagram juga digunakan untuk memperlihatkan aktor yang terlibat didalam sebuah aplikasi [19]. Dimana diagram ini digambarkan dalam bentuk diagram use case. Use case diagram meruapakan "diagram yang mampu menggambarkan atau mengilustrasikan keterkaitan aplikasi dan aktor atau pengguna dari aplikasi [20].

Use case yang menggambarkan sistem yang di usulkan. Dimana sistem yang di usulkan terdiri dari dua aktor yaitu admin dan user. Admin harus login terlebih dahulu kedalam sistem, setelah login admin dapat melakukan pengelolaan data mulai dari, update kota tujuan, jadwal, tempat duduk, dan data pemesanan. Sedangkan user harus regristrasi terlebih dahulu sebelum bisa masuk atau login kedalam sistem. Setelah user masuk kedalam sistem, user bisa melakukan pemesanan tiket mulai dari booking tiket, memilih tempat duduk, 
melihat jadwal keberangkatan serta memilih

kota tujuan.

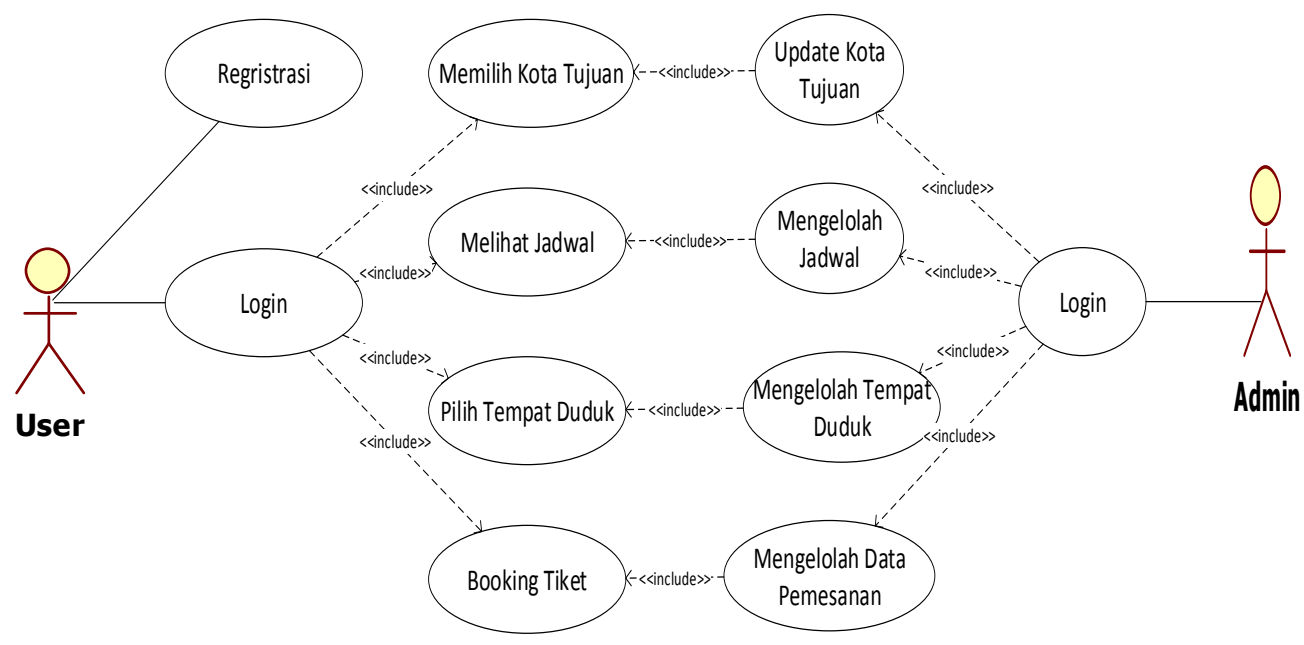

Gambar 2. Use Case Diagram

Selanjutnya adalah pemodelan interaction diagram merupakan diagram dinamik yang mampu menggambarkan bagaimana interaksi antar objek dalam sebuah sistem informasi. Pemodelan interaction diagram dibuat dalam bentuk activity diagram. Activity diagram merupakan salah satu diagram untuk menampilkan prosedur dari dalam proses dari aplikasi. Gambar 2 merupakan salah satu dari activity diagram untuk aplikasi booking tiket.

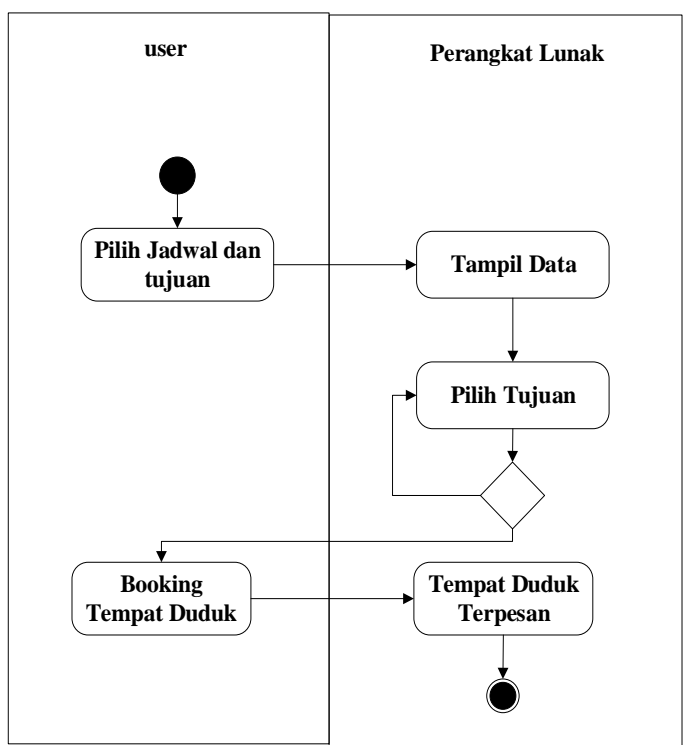

Gambar 3. Activity Diagram

Setelah dua pemodelan sebelumnya maka selanjutnya melakukan pemodelan structure. Pemodelan ini digunakan untuk menggambarkan bagaimana bentuk dari aplikasi yang akan dibangun. Untuk itu dalam pemodelan aplikasi booking tiket menggunakan unified modeling language digunakan class diagram. Class diagram sendiri merupakan diagram yang terbentuk terdiri dari class name, attribute, dan 
method. Dari tiga pembentuk kelas tersebut dapat diketahui bahwa class name digunakan sebagai nama identitas kelas, attribute digunakan sebagai property atau karateristik kelas dan method digunakan sebagai behavior atau tingkah laku dari kelas itu sendiri. pada pemodelan aplikasi booking tiket menggunakan unified modeling language ini terdapat enam kelas yang terdiri dari login yang digunakan untuk data login, pelanggan digunakan untuk data pelanggan, pemsanan digunakan untuk data pememsanan, bus digunakan untuk data bus, jadwal digunakan data jadwal dan rute digunakan untuk data rute. Class diagram dalam aplikasi booking tiket menggunakan unified modeling language seperti yang diperlihatkan pada Gambar 4.

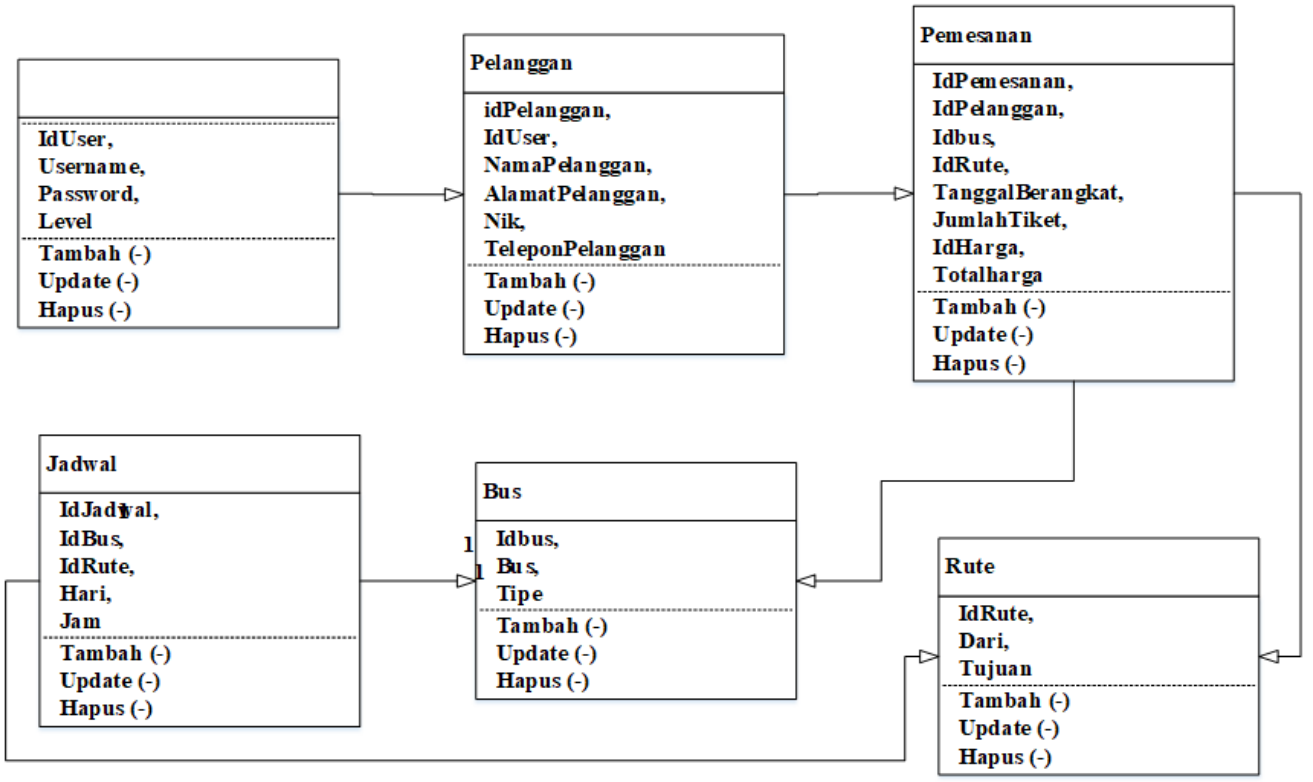

Gambar 4. Class Diagram

\section{HASIL DAN PEMBAHASAN}

Sesuai dengan proses penelitian terhadap pemodelan aplikasi booking tiket menggunakan unified modeling language. Maka hasil penelitian dapat dijelaskan sebagai berikut.

Setelah melakukan pemodelan seperti yang telah dijelaskan sebelumnya maka selanjutnya sesuai dengan proses penelitian dilakukan pembuatan prototype aplikasi. Prototype aplikasi yang dibuat guna untuk memperlihatkan bagaimana aplikasi dibentuk. Sesuai dengan pemodelan pengguna yang dapat melakukan aktivitas terdiri dari dua jenis pengguna yaitu administrator dan pelanggan atau calon penumpang. Gambar 4 merupakan tampilan awal dari administrator booking tiket.

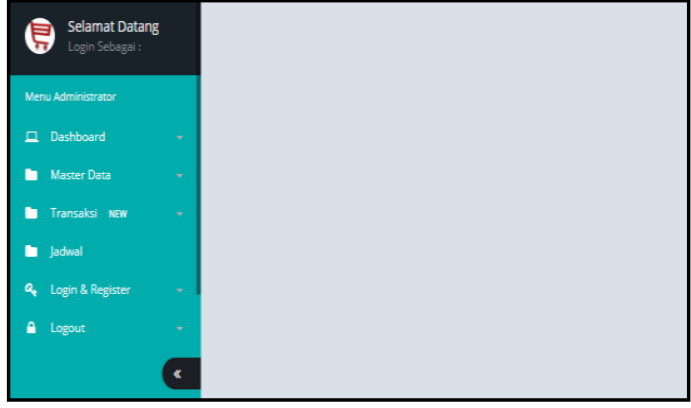

Gambar 5. Menu Utama Administrator

Seperti yang diperlihatkan pada Gambar 5 merupakan tampilan halaman utama administrator dimana pada halaman ini terdapat berbagai macam menu yang dapat digunakan sebagai alat bantu dalam proses pemesanan tiket bus. Seperti yang diperlihatkan pada Gambar 5 merupakan menu untuk melakukan pengelolaan data bus dan kursi pada bus itu sendiri. data bus dan 
kurusi pada bus tersebut digunakan untuk informasi kepada calon penumpang ketika mereka melakukan pemesanan tiket.

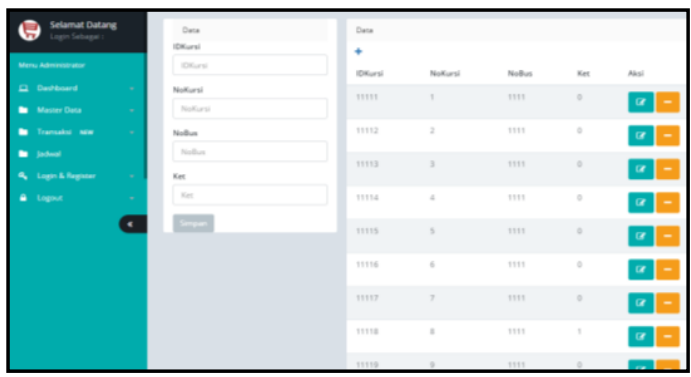

Gambar 6. Data Kursi pada bus

Selain data pengaturan kursi pada bus seperti yang diperlihatkan pada Gambar 6 terpat juga menu informasi pemesanan tiket yang dilaku oleh pelanggan seperti yang diperlihatkan pada Gambar 7.

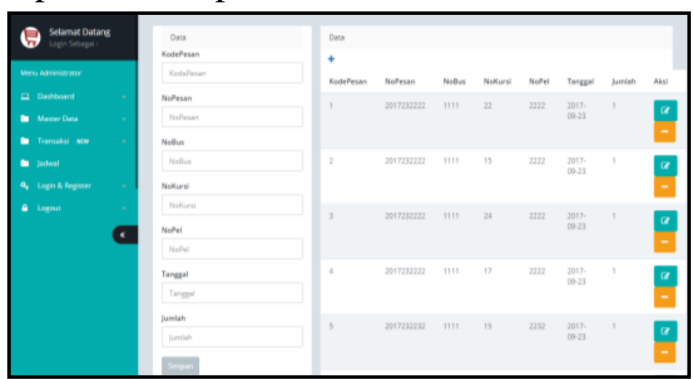

Gambar 7. Data Pemesanan Tiket

Administrator juga dapat melihat informasi konfirmasi pemesanan yang dilakukan oleh pelanggan ketika mereka telah melakukan pemesanan seperti yang ditampilkan pada Gambar 6. Sedangkan konfirmasi merupakan pemberitahuan pembayaran yang dilakukan oleh pelanggan kepada pihak bus. Data tersebut seperti yang diperlihatkan pada Gambar 7.

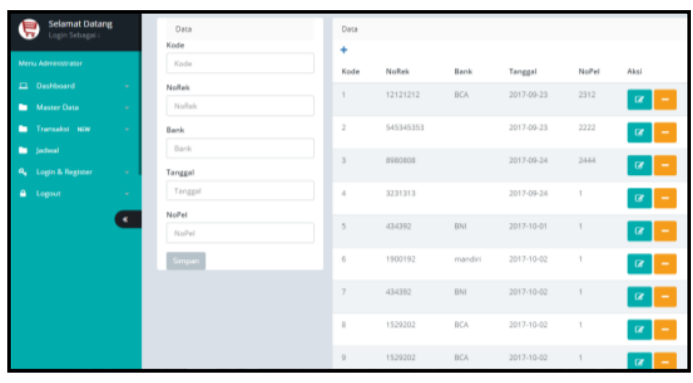

Gambar 8. Data Konfirmasi Tiket
Ketika pelanggan telah melakukan konfirmasi tentang pembayaran mereka maka selanjutnya administrator dapat melakukan approve atau persetujuan dan otomatis akan masuk dalam jadwal keberangkatan. Data jadwal keberangkatan sendiri seperti yang diperlihatkan pada Gambar 8.

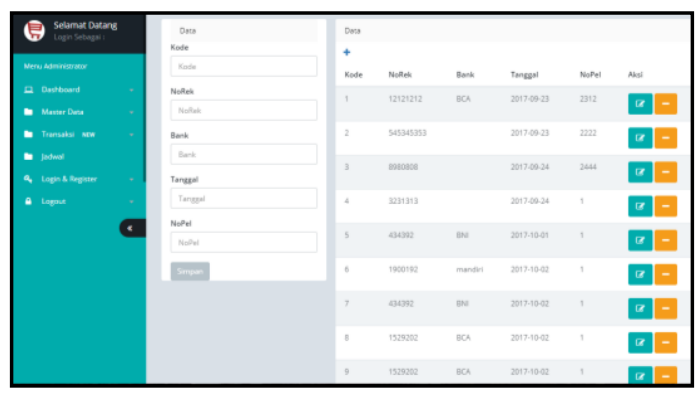

Gambar 9. Data Jadwal Keberangkatan

Selain dari sisi administrator terdapat juga pengguna dari sisi pelanggan seabgai tempat atau proses pemesanan tiket. Untuk melakukan pemesanan tiket maka pelanggan diharuskan untuk melakukan login sebagai bentuk validasi data. Namun jika pelanggan belum memiliki akun maka dapat melakukan pendaftaran sebagai pengguna dengancara mengklik daftar. Namun jika telah memiliki akun makan dapat langsung melakukan login seperti yang diperlihatkan pada Gambar 9 .

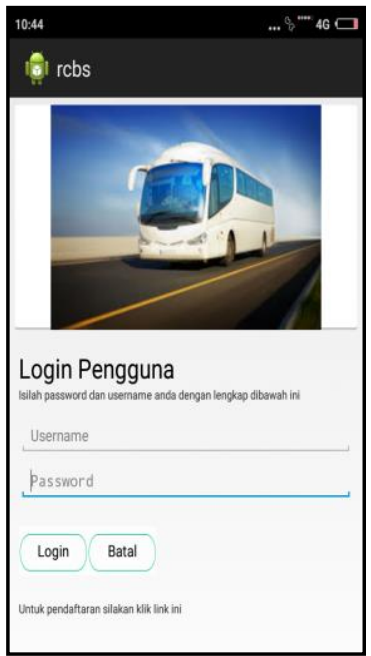

Gambar 10. Login Pelanggan 
Setelah melakukan logi seperti yang diperlihatkan pada Gambar 10 maka pelanggan memiliki empat menu yang dapat digunakan yaitu pesan, jadwal, history dan konfirmasi. Pesan digunakan untuk memesan tiket bus, jadwal digunakan untuk melihat jadwal keberangkatan, history digunakan untuk melihat history pemesanan dan konfirmasi digunakan untuk melakukan konfirmasi pembayaran. Jika pelanggan ingin melakukan pemesanan dengan cara mengklik menu pesan dan akan ditampilkan form pemesanan seperti yang diperlihatkan pada Gambar 10. Ketika memesan tiket bus maka pelanggan diminta untuk memilih kota asal dan tujuan dan waktu keberangkatan. Kondisi tersebut dibutukan guna melihat ketersediaan jadwal keberangkatn.

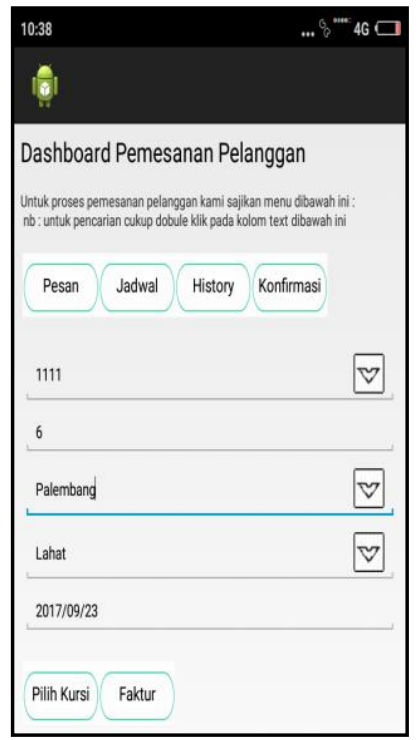

Gambar 11. Pemesanan Tiket

Serelah melakukan pemilihan kota asal, kota tujuan dan tanggal selanjutnya adlaah melakukan pemilihan kuris tempat duduk. Untuk melakukan pemilihan kursi dapat dilakukan dengan cara klik menu pilih kuris maka akan ditampilkan susunan kursi seperti yang diperlihatkan pada Gambar 11 . Sesuai Gambar 11 diperlihatkan gambar kuris yang dapat dipilih oleh pelanggan. Warna kursi terang menunjukkan kuris masi dapat dipilih sedangkan warna kursi abu-abu menunjukkan kursi tidak dapat dipilih.

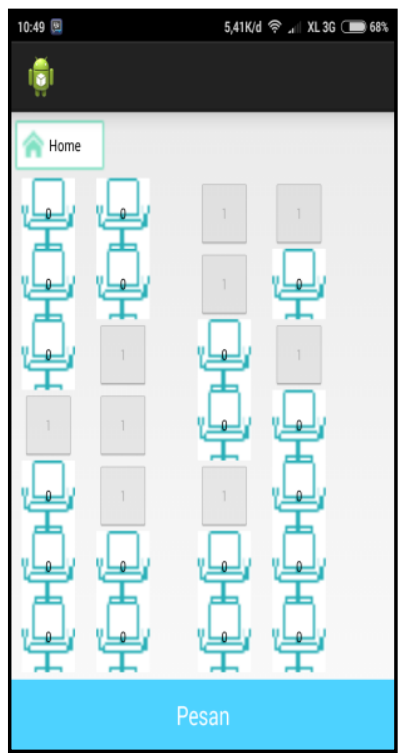

Gambar 12. Pemilihan Kursi

Jika pelanggan telah melakukan pemesanan dan memilih kursi maka pelanggan selanjutnya dapat melakukan konfirmasi pembayaran dengan cara mengklik menu konfirmasi seperti yang diperlihatkan pada Gambar 12.

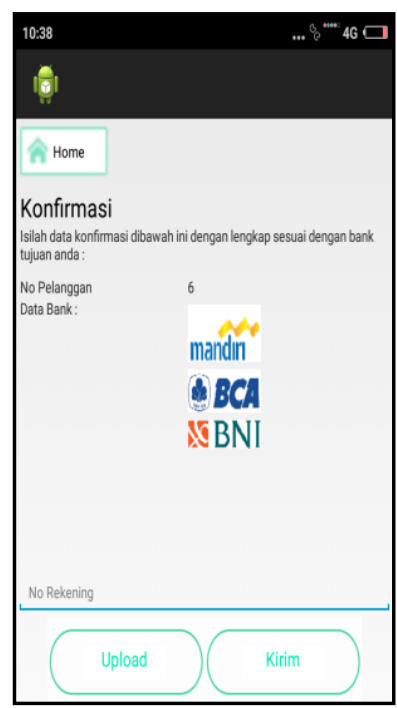

Gambar 13. Konfirmasi Pesanan 


\section{KESIMPULAN}

Sesuai dengan uraian yang telah dikemukakan maka dapat disimpulkan beberapa hal yaitu: (1) pemodelan aplikasi booking tiket menggunakan unified modeling language dapat menjadi alat bantu dalam proses pengembangan aplikasi. (2) pemodelan aplikasi dilakukan menggunakan tiga diagram yaitu use case diagram, activity diagram dan class diagram. (3) prototype aplikasi yang dihasilkan dapat dengan jelas menggambarkan bagaimana aplikasi dibentuk sesuai dengan hasil pemodelan yang dilakukan. (4) protype aplikasi juga dapat memperlihatkan dua jenis pengguna yang berinteraksi dalam aplikasi yaitu administrator berbasis web dan pelanggan berbasis mobile.

\section{SARAN}

Saran yang dapat diberikan terutama bagi peneliti selanjutnya adalah hendaknya melakukan pemodelan dengan menggunakan berbagai diagram agar dapat memperlihatkan alur proses dari aplikasi secara detail.

\section{DAFTAR PUSTAKA}

[1] A. Damanhuri, E. Mujahidin, and D. Hafidhuddin, "Inovasi pengelolaan pesantren dalam menghadapi persaingan di era globalisasi," Ta'dibuna J. Pendidik. Islam, vol. 2, no. 1, pp. 17-37, 2013.

[2] F. Fatmasari and S. Sauda, "Pemodelan Unified Modeling Language Sistem Informasi Enterprise Resource Planning," $J$. MEDIA Inform. BUDIDARMA, vol. 4, no. 2, pp. 429-436, 2020.

[3] A. Syazili, F. Fatoni, and R. Sutejo, "Pemodelan dan Implementasi Perangkat Lunak Berbasis Mobile pada Bina Darma TV," JISKA (Jurnal Inform. Sunan Kalijaga), vol. 3, no. 3, pp. 62-69, 2019.

[4] E. Yulianingsih, N. Oktaviani, and U. Ependi, "Implementasi Simple
Additive Weighting Penentuan Prioritas Penanganan Sumber Air Bersih," J. Sisfokom (Sistem Inf. dan Komputer), vol. 9, no. 1, pp. 77-82, 2020.

[5] H. Hutrianto and A. Putra, "Implementasi Scrum Model Dalam Pengembagnan Aplikasi Pelaporan Sampah Sebagai Wujud Smart Cleaning," JIPI (Jurnal Ilm. Penelit. dan Pembelajaran Inform., vol. 5, no. 1, pp. 9-19, 2020.

[6] F. Syakti and B. Tujni, "Implementasi Simple Multi Attribute Rating Technique Dalam Pemilihan Minat Ekstrakurikuler Siswa," J. Inform., vol. 20, no. 1, pp. $1-12,2020$.

[7] G. Gushelmi and D. R. Kamda, "Pemodelan Uml Sistem Penerimaan Mahasiswa Baru Berา basis Wap (Studi Kasus: Sistem Penerimaan Mahasiswa Baru Upi 'Yptk' Padang)," J. Ilmu Komput., vol. 1, no. 1, pp. 24-44, 2012.

[8] H. Marfalino, "Pemodelan Sistem Informasi Pengontrolan Distribusi Barang Menggunakan UML (studi kasus di CV. Anda Karya Jaya Padang)," J. Teknol. Fak. Teknol. Ind., vol. 4, no. 1, pp. 1-13, 2014.

[9] P. Sulistyorini, "Pemodelan visual dengan menggunakan uml dan rational rose," Dinamik, vol. 14, no. $1,2009$.

[10] M. Maimunah, I. Ilamsyah, and M. Ilham, "Rancang Bangun Aplikasi Penjualan Furniture Online Pada Mitra Karya Furniture," CSRID (Computer Sci. Res. Its Dev. Journal), vol. 8, no. 1, pp. 25-36, 2016.

[11] S. Sutejo, "Pemodelan UML Sistem Informasi Geografis Pasar Tradisional Kota Pekanbaru," Digit. Zo. J. Teknol. Inf. dan Komun., vol. 7, no. 2, 2016.

[12] U. Ependi, "Pemodelan Sistem Informasi Monitoring Inventory Sekretariat Daerah Kabupaten Musi Banyuasin," KLIK-KUMPULAN J. ILMU Komput., vol. 5, no. 1, pp. 4960, 2018. 
[13] H. Abdurahman and A. R. Riswaya, "Aplikasi Pinjaman Pembayaran Secara Kredit Pada Bank Yudha Bhakti," J. Comput. Bisnis, vol. 8, no. 2, pp. 61-69, 2014.

[14] A. Juansyah, "Pembangunan aplikasi child tracker berbasis assisted-global positioning system (a-gps) dengan platform android," J. Ilm. Komput. dan Inform., vol. 1, no. 1, pp. 1-8, 2015.

[15] T. Sugiharto, A. Kadir, and R. Ferdiana, "Perancangan Mobile Application Untuk Penanganan Tindak Pidana Pelanggaran LaluLintas Menggunakan Metode Rational Unified Process," SEMNASTEKNOMEDIA ONLINE, vol. 2, no. 1, pp. 1-13, 2014.

[16] S. Susilowati, "Pengembangan Sistem Informasi Manajemen Zakat, Infaq, Shadaqoh, Waqaf dan Hibah Menggunakan Metode Waterfall," Paradig. Komput. dan Inform., vol. 19, no. 1, pp. 52-60, 2017.

[17] G. Bazydlo, M. Adamski, M. Wegrzyn, and A. R. Munoz, "From UML specification into FPGA implementation," Adv. Electr. Electron. Eng., vol. 12, no. 5, pp. 452-458, 2014.

[18] A. S. Tohir, "Pemodelan Sistem Data Terdistribusi Untuk Mengintegrasikan Data Akademik Dan Keuangan," INTENSIF J. Ilm. Penelit. dan Penerapan Teknol. Sist. Inf., vol. 1, no. 1, pp. 44-52, 2017.

[19] G. Urva and H. F. Siregar, "Pemodelan UML E-Marketing Minyak Goreng," JURTEKSI R. Edisi2, 2015.

[20] F. Purwaningtias and C. Mukmin, "Pemodelan Enterprise Resource Planning Menggunakan Odoo Pada Z-Tech Komputer," KLIKKUMPULAN J. ILMU Komput., vol. 6, no. 3, pp. 275-283, 2019. 